\title{
OSTEOBLASTOMA OF PATELLA: A RARE CASE
}

\author{
S. Krishna Kumari ${ }^{1}$, Prasad Uma ${ }^{2}$, Raja Pramila ${ }^{3}$, H. L. Vasavi ${ }^{4}$, L. Prasanna Kumar ${ }^{5}$
}

\section{HOW TO CITE THIS ARTICLE:}

S. Krishna Kumari, Prasad Uma, Raja Pramila, H. L. Vasavi, L. Prasanna Kumar. “Osteoblastoma of Patella: A Rare Case". Journal of Evolution of Medical and Dental Sciences 2015; Vol. 4, Issue 17, February 26; Page: 2979-2983, DOI: $10.14260 /$ jemds/2015/430

ABSTRACT: Benign osteoblastoma of patella is a rare tumor. Majority of the tumors occur in spine, femur and tibia. Osteoblastoma presents as a diagnostic dilemma due to clinical similarity with other benign bone forming tumors. Histopathological examination is the main stay for diagnosis and has good prognosis.

KEYWORDS: Osteoblastoma, patella, rare.

CASE REPORT: A 16 year old boy from Srikakulam district presented to the outpatient department of orthopedics in the year 2012 with a six year history of knee pain and swelling of the left knee gradually increasing in size. The pain was worst at night. Six years back before the present swelling the boy had taken treatment for injury of left knee which healed after therapy. (Fig. 1)

On physical examination the patella was painful with significant swelling compared to the contralateral side. Articular range of motion was normal. Haemogram, CRP, and ESR were completely normal. Standard lateral and AP view of X-ray patella showed a well circumscribed lesion of $5 \times 3 \times 3$ $\mathrm{cm}$ size with mixed echogenicity. Both radiopaque and radio lucent areas rimmed by sclerotic margins.(Fig. 2) CT scan of the left knee confirmed the presence of fluid filled multi septate cavities suggesting the diagnosis of aneurysmal bone cyst / hemangioma. FNAC was performed and the aspiration showed only blood and blood cellular elements.

Patellectomy was done with widely excised margins and the specimen was sent for histopathological examination. On gross examination the specimen measured $5 \times 5 \times 4 \mathrm{cms}$ and cut section showed red granular surface with cystic spaces and tan white areas. It was gritty to cut and rimmed by sclerotic bone. (Fig. 3)

On microcopy multiple sections showed anastamosing bony trabeculae irregularly arranged in a loose fibro vascular stroma. The trabeculae were lined by rim of osteoblasts which were polygonal in shape with moderate eosinophilic cytoplasm, round to oval nuclei and single nucleoli. Osteoid was seen. (Fig. 4) In addition there were large dilated vascular channels which had septae. In the septae there was loosely arranged spindle cells, osteoclastic giant cells, areas of hemorrhage and hemosiderin laden macrophages with adjacent foci of mature cartilage. (Fig. 5, 6). The diagnosis offered was Osteoblastoma with secondary ABC changes.

The pain was completely relieved and the patient commenced normal exercise 48 hours after the operation. After 18 months, the follow up X-ray showed completely healed bone. On follow up further, the patient is fine till date without pain and recurrence of the lesion.

DISCUSSION: Osteoblastoma is a rare benign tumor that accounts for less than $1 \%$ of all primary bone neoplasms. The neoplasm may be intramedullary, cortical, or sub periosteal in location. Sixty to sixty-five percent of the osteoblastomas are cortical and the remainder is medullary.[1] Osteoblastoma is usually diagnosed in young adults in the $2^{\text {nd }}$ to $4^{\text {th }}$ decade of life and males are affected approximately twice as frequently as females.[2] 


\section{CASE REPORT}

Jackson et al.[3] reported $35 \%$ percent of osteoblastomas in the spine, $10 \%$ in the femur, $5 \%$ in the tibia and $9 \%$ in the bones of the foot and ankle in a series of 184 patients. Lucas et al..[4] reported $32 \%$ in the vertebral column, $12 \%$ in the femur, and $10 \%$ in the tibia.

J Singh et al.[5] in their study analyzed fifty-nine cases of lesions presenting in the patella. Of the 59 cases, $46 \%$ were non neoplastic, 39\% were benign and 15\% were malignant. The commonest benign neoplasm was giant cell tumor (11 cases). Younger patients were more likely to have a benign neoplasm. Lesions in patients less than 40 years of age included giant cell tumor, chondroblastoma, aneurysmal bone cyst (ABC), osteomyelitis, osteoid osteoma and solitary bone cyst. In patients older than 40 years, the following were common lesions: intra-osseous gout, metastasis and intra-osseous ganglion. Osteoblastoma arising from the patella is rare.

Osteoblastoma presents as a diagnostic dilemma and difficult to differentiate from other benign bone forming tumors. The following lesion has to be differentiated from osteoblastoma and histopathological examination is essential to differentiate these various lesions. The salient features on histopathology, which differentiate osteoblastma from other lesions, are:

In osteoblastma there are anastamosing trabeculae of osteoid and woven Bone, rimmed by single layer of benign osteoblasts. Loose fibro vascular stroma is seen between bony trabceulae with numerous osteoclasts. Intralesional hemorrhage and secondary ABC areas can be seen.[6] Sometimes cartilage is seen.[7]In the present case secondary $A B C$ like areas and cartilage was seen which is uncommon. The tumor does not permeate into the adjacent bony trabaculae and the mitotic activity is low.

In aggressive osteoblastoma the features are similar to benign osteoblastoma except for the morphology of osteoblasts which are large and have epitheloid appearance. The osteoblasts are arranged in single cell layer and in aggregates, which are twice the size of normal osteoblasts. The cytoplasm is abundant eosinophilic with eccentric vesicular nuclei and prominent nucleoli. Mitosis and necrosis are not seen.

In osteoid osteoma the microscopic features are similar to osteoblastoma. The only differentiating features is size of the tumor which is less than $2 \mathrm{~cm}$. Osteoblastoma like Osteosarcoma resembles osteoblastoma, but permeation in to the surrounding host tissue is the diagnostic feature.

In aneurysmal bone cyst there are large cystic spaces filled with blood and separated by fibrous septa, alternating with solid area. The cystic spaces and septa are lined by fibroblasts, myofibroblasts, histiocytes but not endothelium; clusters of osteoclastic like multinucleated giant cells may be seen.

The stroma is more cellular showing spindle cells. Reactive woven bone, degenerated calcified and fibromyxoid tissue is sometimes seen.

Definitive diagnosis and clear treatment plan will prevent recurrence of osteoblastoma with good prognosis. 


\section{CASE REPORT}

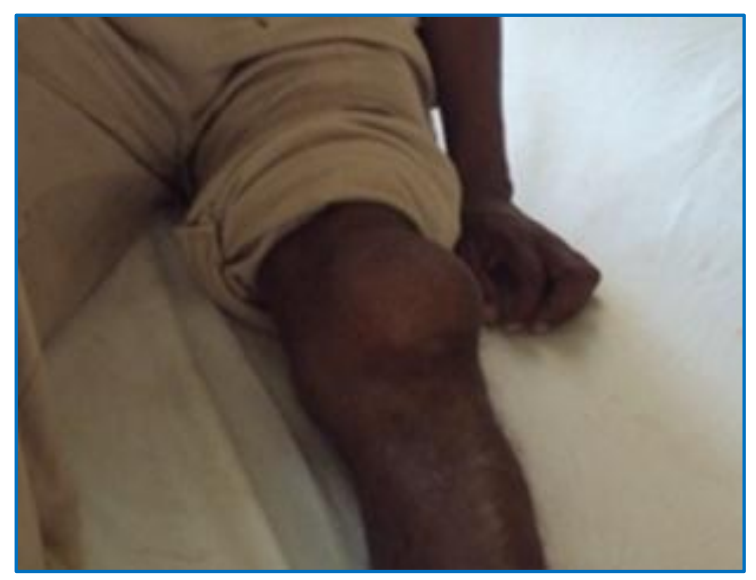

Fig. 1: Clinical picture - swelling Of left knee joint

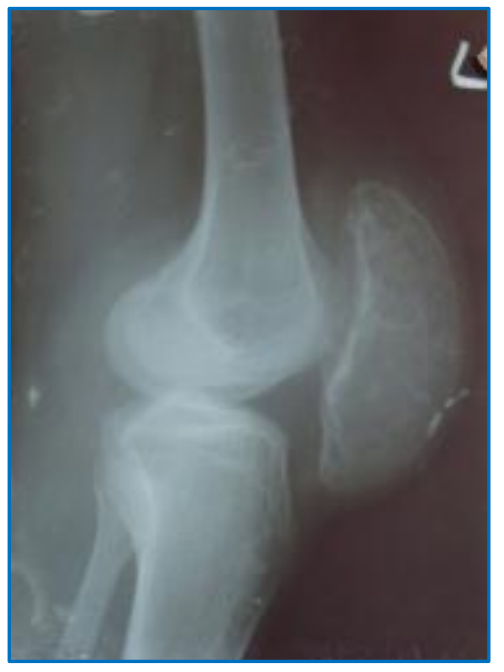

Fig. 2: X-ray lateral view - expansile cystic and lytic lesion of patella with rim of sclerotic bone

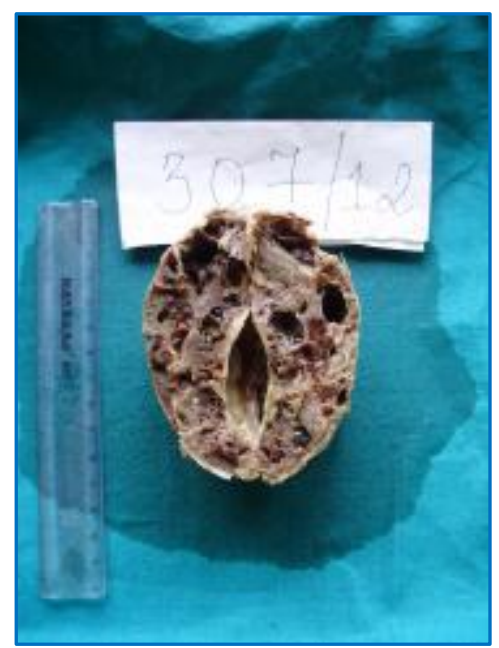

Fig. 3: Gross specimen- patella on cut section showing hemorrhagic and cystic areas with intervening bony septa

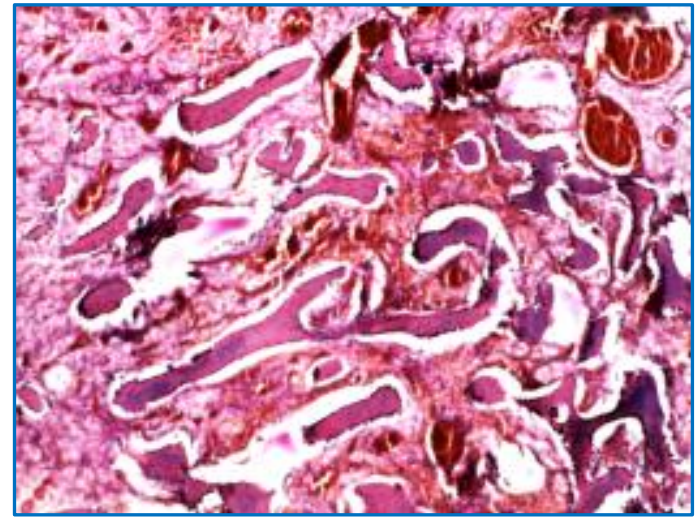

Fig. 4: Small irregular bony trabeculae with osteoid and vascularised fibro connective tissue. (H\&E,100X) 


\section{CASE REPORT}

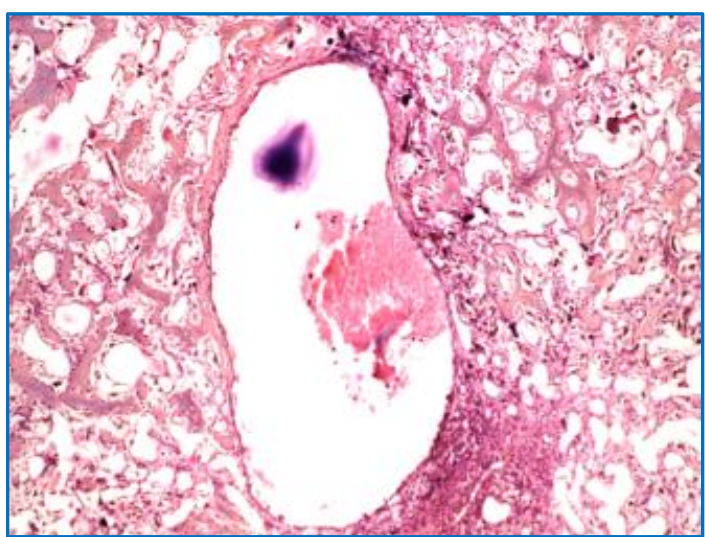

Fig. 5: ABC like areas (H\&E, 100X)

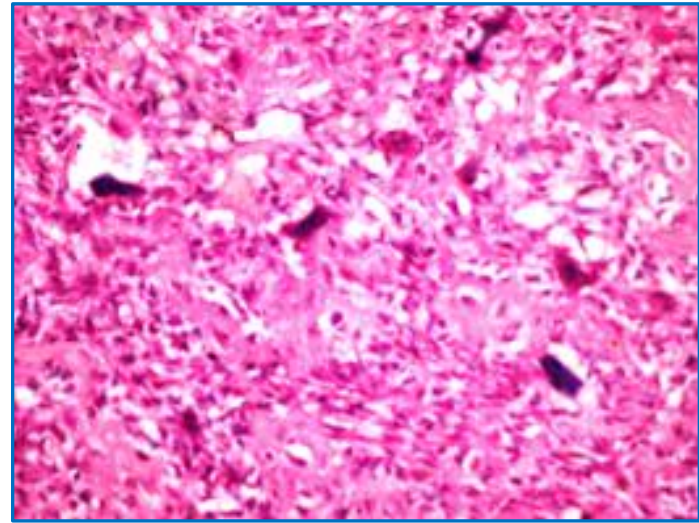

Fig. 6: Osteoclast giant cells with spindle cells in the septa (H\&E,400X)

\section{REFERENCES:}

1. Vipul Sharma, Felix S. Chew, Benjamin Hoch. Periosteal osteoblastoma: Multimodal imaging of a rare neoplasm. Radiology Case Reports.2009; 4: No 4

2. Berry M, Mankin H, Gebhardt M, Rosenberg A, Hornicek F.Osteoblastoma: a 30-year study of 99 cases. J Surg Oncol. 2008 Sep 1; 98 (3):179-83

3. Jackson RP, Reckling FW, Mants FA. Osteoid osteoma and osteoblastoma. Similar histologic lesions with different natural histories. Clin Orthop Relat Res. 1977 Oct ;(128):303-13.

4. Lucas DR, Unni KK, McLeod RA, O'Connor MI, Sim FH. Osteoblastoma: clinicopathologic study of 306 cases. Hum Pathol. 1994 Feb; 25 (2):117-34

5. J. Singh, S. L. James, H. M. Kroon, K. Woertler, S. E. Anderson, A. M. Davies. Tumour and tumourlike lesions of the patella - a multicentre experience. European Radiology. 2009; Volume 19: 701-712

6. Martinez V, Sissons HA. Aneurysmal bone cyst. A review of 123 cases including primary lesions and those secondary to other bone pathology. Cancer. 1988 Jun 1;61(11):2291-304

7. Mortazavi SM, Wenger D, Asadollahi S, Shariat Torbaghan S, Unni KK, Saberi S.Periosteal osteoblastoma: report of a case with a rare histopathologic presentation and review of the literature. Skeletal Radiol. 2007 Mar; 36(3):259-64. 


\section{CASE REPORT}

\section{AUTHORS:}

1. S. Krishna Kumari

2. Prasad Uma

3. Raja Pramila

4. H. L. Vasavi

5. L. Prasanna Kumar

\section{PARTICULARS OF CONTRIBUTORS:}

1. Professor \& HOD, Department of Pathology, RIMS, Srikakulam, A.P.

2. Associate Professor Department of Pathology, RIMS, Srikakulam, A.P.

3. Associate Professor Department of Pathology, RIMS, Srikakulam, A.P.

FINANCIAL OR OTHER COMPETING INTERESTS: None
4. Assistant Professor, Department of Pathology, RIMS, Srikakulam, A.P.

5. Orthopaedic Surgeon, Department of Orthopaedic, RIMS, Srikakulam, A.P.

NAME ADDRESS EMAIL ID OF THE CORRESPONDING AUTHOR:

Dr. Prasad Uma,

Q. No. 49-3-3,

Lalithanagar, Vishakapatnam,

Andhra Pradesh-530016.

E-mail: usha1966411@gmail.com

Date of Submission: 28/01/2015. Date of Peer Review: 29/01/2015. Date of Acceptance: 17/02/2015. Date of Publishing: 25/02/2015. 